экспертизы, позволит в оптимальные сроки выполнить назначенные судебные железнодорожно-транспортные экспертизы и предоставить обоснованные выводы.

Ключевые слова: железнодорожно-транспортное происшествие, катастрофа, авария, безопасность движения, служебное расследование, железнодорожно-транспортная экспертиза.

\title{
METHODOLOGICAL APPROACHES TO CARRYING OUT THE OFFICIAL INVESTIGATION OF THE RAILWAY ACCIDENT IN UKRAINE AND ABROAD
}

\section{Dzhus O. V.}

While transporting passengers and cargo by rail transport, there is always a risk of an unusual situation arising as a result of exposure to various factors or actions of people (operators) namely a railway transport accident. In case of such a situation official (special) investigations are performed; the reasons for its occurrence are detected. Materials, testimonies and facts determinated while performing this type of investigation are important enough and used while carrying out the research in the framework of railway transport forensic examination. All efforts to improve the methods of investigating the causes and factors of influence on the occurrence of railway transport accidents are reduced to one goal: improving the quality of their investigation and preventing crashes and catastrophes in rail transport in the future. There are certain methodological approaches while conducting an official investigation of railway transport accidents abroad (in the Baltic States, Kazakhstan, Russia) and in Ukraine. The process of performing an official investigation in Ukraine is examined in detail according to current Methodological Guidelines. Work towards improving and perfection these approaches has been ongoing and this has undoubtedly been positively reflected on the research process within the frameworks of implementation of forensic railway transport examinations. It should be also noted that the competent, complete and high-quality execution of materials submitted to forensic experts for performing examination will allow to fulfill the assigned forensic railway transport examinations and provide substantiated conclusions in optimal time frame.

Keywords: railway transport accident, catastrophe, crash, traffic safety, official investigation, railway transport examination.

DOI: https://doi.org/10.32353/khrife.2018.50

УДК 343.148.6:629.4.017

A. B. Батіг, старший науковий співробітник Львівського НДІСЕ, магістр

E-mail: batigasha1992@gmail.com

\section{АНАЛІТИЧНЕ ВИЗНАЧЕННЯ КРИТЕРІЇВ БЕЗПЕКИ РУХУ НА ЗАЛІЗНИЧНОМУ ТРАНСПОРТІ}

Виконано перевірку умов стійкості від сходу з рейок рухомого складу за прийнятими нормами для вагона моделі 11-286. Наведено основні недоліки використаного методу розрахунку та способи його вдосконалення.

Ключові слова: схід з рейок рухомого складу, катастрофа, аварія, безпека руху, стійкість від сходу з рейок. 
Здатність залізничного транспорту задовольняти потреби щодо перевезень пасажирів, вантажів при безумовному забезпеченні безпеки руху визначає його розвиток і досягнення ним провідних позицій на ринку перевезень. Найважливішою проблемою на залізничному транспорті є забезпечення безпеки руху рейкових екіпажів як на етапі проектування, так і в процесі їх експлуатації. При цьому запобігання транспортним подіям на залізницях має першочергове значення.

Ряд транспортних подій, що мали місце на залізничному транспорті України в останні роки, послужили серйозним попередженням для вживання невідкладних заходів із забезпечення безпеки руху. Аварії та катастрофи спостерігаються на всіх залізницях світу, і їх наслідками є людські жертви, забруднення довкілля та значні матеріальні збитки.

Одним із показників взаємодії колії й рухомого складу, невиконання якого веде до загрози безпеці руху, а саме до сходу з рейок рухомого складу, $\epsilon$ умова забезпечення стійкості від вкочування гребеня колеса на головку рейки.

Постановка проблеми. Існуюча шкала граничних значень динамічних показників, за якою оцінюється стійкість від сходу рухомого складу залізниць з рейок, недостатня для оцінювання безпеки руху й не враховує технічний стан та індивідуальні параметри ходових частин екіпажів і колії. У зв'язку 3 цим існує необхідність аналізу критерію стійкості кінематичної пари «колесо-рейка».

Аналіз попередніх досліджень. Понад сто років тому в 1908 р. М. Надалем $^{1}$ був запропонований спосіб визначення співвідношення діючих на колесо сил, за якого схід колеса з рейки не відбувається.

Вихідним положенням колеса при цьому вважається таке, за якого його поверхня кочення піднялась над головкою рейки, і колесо контактує з рейкою тільки в точці, яка розташована на конічній частині гребеня. Прийнято, що схід колеса з рейки не відбудеться, якщо співвідношення прикладених до колеса сил - горизонтальної поперечної $Y$ і вертикальної $Q$ (при дії максимальної сили сухого тертя $T=\mu N$ ) буде таким, що гребінь відносно рейки буде ковзати вниз (рисунок).

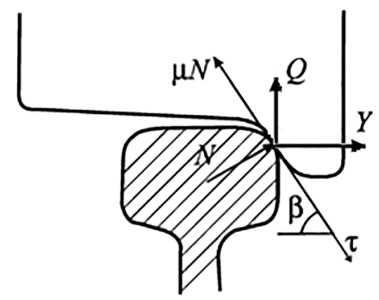

Рисунок. Сили, що діють у точці контакту при ковзанні гребеня вниз відносно головки рейки

1 Nadal M. J. Locomotives a Vapeur. Collection Encyclopedie Scientifique Bibliotèque de Mecanique Applique et Genie. Paris, 1908. Vol. 186. 
Формула Надаля має такий вид (1):

$$
\frac{Y}{Q}<\frac{\operatorname{tg} \beta-\mu}{1+\mu \cdot \operatorname{tg} \beta}
$$

У своїй роботі Г. Мар' $\epsilon^{1}$ зазначає, що при додатному куті набігання $\alpha$ необхідно внести поправку, прийнявши до уваги коефіцієнт тертя ковзання для ненабігаючого колеса й рейки.

Умова стійкості з урахуванням поправок Мар'є має такий вид:

$$
\frac{Y}{Q}<\frac{\operatorname{tg} \beta-\mu}{1+\mu \cdot \operatorname{tg} \beta}-\frac{Q^{\prime}}{Q} \cdot \mu^{\prime}
$$

де $Q^{\prime}$ - навантаження на рейку від ненабігаючого колеса; $\mu^{\prime}$ - відповідний коефіцієнт тертя ковзання.

У роботах, виконаних під керівництвом професора М. Ф. Вериго ${ }^{2}$, був запропонований метод оцінювання стійкості руху проти сходу колеса з рейок за уточненою формулою, яка визначає критичну величину відношення горизонтальної рамної сили та вертикальної сили при цьому розподілі вертикальних навантажень на осі однієї й тієї самої колісної пари. Наведена в цих роботах уточнена умова знайшла широке застосування в експериментальних роботах з визначення гранично допустимих швидкостей руху нових і модернізованих одиниць рухомого складу.

$$
\frac{Y_{p}}{P_{1}} \leq \frac{P_{2}}{P_{1}} \cdot k_{1}-k_{2}+k_{3} \cdot \frac{K}{P_{1}}
$$

де $Y_{p}$ - рамна сила; $P_{1}, P_{2}$ - сили, що діють на колісні пари від надресорної будови екіпажу; $K$ - половина ваги колісної пари; $I_{1}, I_{2}-$ вертикальні сили інерції колісної пари; $k_{1}, k_{2}, k_{3}$ - коефіцієнти.

У роботі ${ }^{3}$ вирішення цієї задачі проведено з використанням рівнянь статики. При цьому передбачається, що в разі втрати рівноваги колісна пара буде переміщатися тільки в напрямку, перпендикулярному осі колії. Рух же вздовж осі не розглядається; отже, не враховуються й сили тертя ковзання, що виникають у цьому напрямку. Крім того, складові сил тертя ковзання, що виникають у поздовжньому й перпендикулярному до осі колії напрямках, визначені в найзагальнішому виді та не можуть бути використані для практичного застосування.

У роботі ${ }^{4}$ для оцінювання небезпеки сходу рухомого складу шляхом вкочування колеса на головку рейки пропонується використовувати комбі-

1 Марье Г. Взаимодействие пути и подвижного состава. Москва : Госжелдориздат, $1933.338 \mathrm{c.}$

2 Вериго М. Ф. Взаимодействие пути и подвижного состава. Москва : Транспорт, 1986. 559 с.; Бромберг E. M. Взаимодействие пути и подвижного состава. Москва : Гострансжелдориздат, 1956. 280 с.

3 Шахуняни Г. М. Железнодорожный путь. Москва : Транспорт, 1987. 479 с.

4 Погорелов Д. Ю. Критерий для оценки опасности схода подвижного состава путем вкатывания колеса на головку рельса. Подвижной состав XXI века: идеи, требования, проекты. 2009. С. 136-138. 
нований критерій. У цій роботі замість коефіцієнта тертя пропонується використовувати відношення поперечної складової сили крипу до нормальної реакції в точці контакту.

У роботі ${ }^{1}$ формулюється енергетичне трактування вкочування колеса на головку рейки. На думку авторів, це можливо тоді, коли кінетична енергія руху, яка припадає на колісну пару, перевершує ту роботу сил, що виникають у місці контакту поверхонь гребеня й колеса, яку вони здійснюють при підйомі на висоту гребеня. Запропонована схема оцінювання запасу стійкості враховує вплив основних факторів, що спричиняють виникнення аварійного стану.

У роботі ${ }^{2}$ порівнюються північноамериканський, британський і європейський підходи щодо оцінювання безпеки руху. Автори доходять висновку, що британські та європейські критерії застосовують граничні значення сил, які передаються від екіпажа на колію. Північноамериканський підхід не обмежує максимальні сили, що діють на колію, а обмежує статичні навантаження. У британському підході є обмеження і на вертикальні, і на горизонтальні сили, а в європейському - тільки на горизонтальні поперечні.

У роботі ${ }^{3}$ автор пропонує розглядати відношення горизонтальної поперечної сили до вертикальної для двох коліс колісної пари, одне з яких набігає на головку рейки. Критерій Вейнстока, на відміну від критерію Надаля, $є$ менш чутливим до значення коефіцієнта тертя ковзання. Особливо це помітно при його високих значеннях $(0,3-0,7)$, що дуже важливо при проведенні аналізу ходових випробувань, де визначення величини $\mu \in$ складним завданням.

У чинній нормативній літературі ${ }^{4}$ при оцінюванні сходу колеса з рейки пропонується використовувати «коефіцієнт запасу стійкості проти вкочування колеса на головку рейки». При цьому вважається, що в разі, коли значення цього коефіцієнта менше одиниці, колісна пара може зійти з рейок. Однак при виведенні цього критерію не враховувалися багато факторів, у тому числі й такі як кут набігання колісної пари та тривалість дії сил.

Слід зазначити, що в роботі ${ }^{5}$ для визначення умови безпеки від сходу колісної пари з рейки автор пропонує розглядати не схід одного окремо

1 Азовский А. П. Об оценке запаса устойчивости колеса от выкатывания на головку рельса. Безопасность движения поездов : сб. статей междунар. конф. 2007. C. VI-1-VI-2.

2 Elkins J. New Criteria for Flange Climb Derailment. 2000 ASME/IEEE Joint Railroad Conference. 2000. April. P. 1-7.

3 Weinstock $H$. Whell Climb Derailment Criteria for Evaluation of Rail Vehicle Safety. ASME Winter Annual Meeting. 1984. P. 34-42.

4 Нормы расчета и оценки прочности несущих элементов и динамических качеств моторвагонного подвижного состава ж. д. МПС РФ колеи 1520 мм. Москва : МПС РФ, ВНИИЖТ, 1997. 147 с.; Нормы расчета и проектирования вагонов железных дорог МПС колеи 1520 мм (несамоходных) с изменениями. Москва : ГосНИИВВНИИЖТ, 1996. 346 с.

5 Клименко И. В. Развитие теоретических основ и методов оценки и повышения безопасности движения подвижного состава железных дорог. Днепропетровск : 2015. 284 c. 
взятого колеса, а колісної пари в цілому, причому приймати її як тверде тіло. При цьому необхідно розглянути можливий рух колісної пари при ковзанні у вертикальній поперечній площині гребеня колеса, яке набігає на головку рейки.

Мета статті - на конкретному прикладі показати аналітичний розрахунок критеріїв безпеки руху за прийнятими нормами; навести основні недоліки цього методу розрахунку та способи його вдосконалення.

Основний матеріал досліджень. Стійкість колісної пари від сходу 3 рейок перевіряється для найбільш небезпечних випадків поєднання великої поперечної сили від набігаючого колеса на рейку й малого вертикального навантаження на це колесо. При одночасному поєднанні цих сил протягом деякого часу є можливим вкочування гребеня набігаючого колеса на головку рейки, а отже сходу вагона з рейок. Критичне поєднання діючих на колісну пару сил може виникнути в таких трьох випадках:

— при ударному входженні вагона в криву, при проходженні стрілок на бокову колію, при інтенсивному вилянні візка при русі з максимальною швидкістю на прямій ділянці колії, при інтенсивних бокових коливаннях і супутніх несприятливих обставинах взаємодії колісної пари й колії;

- при екстреному гальмуванні поїздів підвищеної ваги на малій швидкості з головного локомотива при проходженні составом кривої ділянки колії, коли значні квазістатичні сили стиснення состава можуть призвести до перекосу (зсуву) вагона в колії й виникнення великих поперечних сил взаємодії коліс із рейками, а в екстремальних умовах - i до витискання легковагового вагона;

— при проходженні з малою швидкістю вагоном перехідної кривої, коли виникає силове замикання скользунів, розташованих по діагоналі вагона i, як наслідок, виникнення кососиметричних сил і обезвантаження коліс.

Методику визначення коефіцієнта запасу стійкості від вкочування гребеня на головку рейки для цих випадків детально наведено в зазначених нормах.

Для прикладу розрахуємо коефіцієнт запасу стійкості від сходу з рейок для порожнього вантажного вагона моделі 11-286 при вкочуванні колеса його колісної пари на зовнішню рейку для другого розрахункового випадку. Коефіцієнт запасу стійкості колісної пари визначається за формулою:

$$
k_{y c}=\frac{\operatorname{tg} \beta-\mu}{1+\mu \cdot \operatorname{tg} \beta} \cdot \frac{P_{\sigma}+2 \gamma N\left\{\left[\frac{\delta_{0} L}{l^{2}}\left(1+\frac{L}{a}\right) h_{n} \pm \alpha \frac{L_{c}}{R} h_{a}\right]\right\} \frac{1}{2 S} \mp 2 P_{s c m} \cdot \frac{h_{p}}{2 S} \cdot \frac{h_{u}}{2 S}}{\mu P_{\sigma}+2 \gamma N\left\{\left[\frac{\delta_{0} L}{l^{2}}\left(1+\frac{L}{a}\right) \pm \alpha \frac{L_{c}}{R}\right] \cdot\left(1-\mu \frac{h_{a}}{2 S}\right) \mp \mu \alpha \frac{L_{c}}{R}\left(\frac{h_{a}-h_{n}}{S}\right)\right\} \mp 2 P_{s c m} \cdot \frac{h_{p}}{2 S}\left(1-\mu \frac{h_{u}}{2 S}\right)} \geq\left[k_{y c}\right],
$$

де $P_{6}-$ вертикальне навантаження від візка на колію з урахуванням його обезвантаження при ексцентричній дії поздовжніх сил; $P_{\text {вст }}$ - вертикальне статичне навантаження від візка на колію; $\gamma, \alpha$ - коефіцієнти перекосу; $N$ розрахункові поздовжні стискаючі сили, які діють на автозчепи вагона. Через те, що процес витиснення є відносно довгим, у розрахунку враховується час дії (більше 3 c) квазістатичних сил, вони приймаються рівними: для порож- 
нього 4-вісного вантажного вагона - 0,5 $M H ; 2 \delta_{0}$ - сумарний вільний поперечний розбіг рами кузова вагона відносно осі колії в напрямку перерізу по шворню (за рахунок поперечних розбігів колісних пар у рейковій колії, рами візка відносно колісних пар, надресорної балки відносно рами (візка) i шворневої балки кузова відносно надресорної балки) рекомендується приймати: для вантажних вагонів з безлюльковим ресорним підвішуванням $2 \delta_{0}=0,05 \mu ; 2 l, 2 L, 2 L_{c}-$ відповідно база вагона, відстань між упорними плитами автозчепів і довжина вагона по осях зчеплення автозчепів, $\mu ; a-$ довжина корпусу автозчепу від осі зчеплення до кінця хвостової частини, для автозчепу СА-3 приймається $a=1, h_{n}, h_{u}$ - відповідно висоти робочої площини підп'ятників і осі автозчепу над рівнем головок рейок, $\mathcal{M} ; h_{\mathrm{p}}-$ підвищення зовнішньої рейки в кривій, рекомендується приймати $h_{p}=0,08 \mathrm{M}$; $2 S$ - відстань між колами катання коліс, приймається $2 S=1,6 \stackrel{p}{M} ; R-$ радіус кривої, приймається $R=250 \mathrm{M}$.

У формулі (4) верхні знаки відповідають розташуванню вагона, коли набігаюче колесо вкочується на зовнішню рейку, а нижні - розташуванню вагона, коли набігаюче колесо вкочується на внутрішню рейку.

Коефіцієнти $\gamma$ і $\alpha$ визначаються за формулами:

$$
\begin{array}{r}
\gamma=\frac{1}{1-\frac{N}{N_{\text {ка }}},} \\
\alpha=\frac{1-\frac{N}{N_{\text {ка }}},}{1-\frac{N}{N_{\text {кб }}}},
\end{array}
$$

де $N_{\text {ка }}$ і $N_{\text {кб́ }}$ - поздовжні критичні сили, що призводять до відносного перекосу вагонів і осей автозчепів у плані, $\kappa H$. Вони визначаються з виразів:

$$
\begin{gathered}
N_{\text {ка }}=\frac{C_{\text {г }}}{1+\frac{L}{a}} \cdot \frac{l^{2}}{L}, \\
N_{\text {кб }}=a \cdot C_{\text {г }},
\end{gathered}
$$

де $C$ - горизонтальна (поперечна) жорсткість ресорного підвішування візка, $\kappa H / M^{\mathrm{r}}$.

При визначенні $k_{\text {ус }}$ необхідно перевірити виконання умови:

$$
\delta_{\mathrm{y}}<\left[\delta_{\mathrm{y}}\right],
$$

де $\delta_{\mathrm{y}} \mathrm{i}\left[\delta_{\mathrm{y}}\right]-$ відповідно пружна поперечна деформація ресорних комплектів візків при дії поперечних горизонтальних сил $H$, прикладених до підп'ятників візків, і граничне (по конструкції) поперечне одностороннє переміщення надресорної балки відносно рами візка. 
Горизонтальна сила визначається за формулою:

$$
H_{1,2},=\gamma N\left[\frac{\delta_{0} L}{l^{2}}\left(1+\frac{L}{a}\right) \pm \alpha \frac{L_{c}}{R}\right] .
$$

При $\delta_{\mathrm{y}} \geq\left[\delta_{\mathrm{y}}\right]$ у формулі $(10)$ необхідно замість $\delta_{0}$ підставляти $\delta_{0}+\left[\delta_{\mathrm{y}}\right]$ і приймати $N_{\text {ка }}=N_{\text {кб́ }}=\infty$.

Розрахунок проводиться для порожнього стану вагона за наявності підвищення зовнішньої рейки $h_{\mathrm{p}}=0,15 \mathrm{~m}$ і $h_{\mathrm{p}}=0$.

Тепер перейдемо безпосередньо до розрахунків.

Визначимо вертикальне навантаження від візка на колію:

$$
P_{6}=\frac{264,87}{2}-\frac{500 \cdot \frac{0,08}{2}\left(\frac{7,875+6,12}{12,24}-\frac{7,875}{6,12} \cdot \frac{1}{1-\frac{6674,64 \cdot 6,12^{2}}{500 \cdot 7,875}}\right)}{1-\frac{500}{2 \cdot 6674,64}\left(1-\frac{7,875^{2}}{6,12^{2}} \cdot \frac{1}{1-\frac{500 \cdot 7,875}{6674,64 \cdot 6,12^{2}}}\right)}=109,747 \kappa H .
$$

Визначимо горизонтальну жорсткість пружини за формулою:

$$
C_{2}=\frac{3 \cdot E \cdot d^{4}}{8 \cdot D \cdot n_{p}\left[H^{2}(2+\mu)+3 D^{3}\right]},
$$

де $H$ - висота пружини під вертикальним навантаженням, м; $E$ - модуль пружності, $E=2 \cdot 10^{8} \kappa H / M^{2} ; \mu-$ модуль Пуассона, $\mu=0,28$.

Висота пружини під вертикальним навантаженням порожнього вагона становить:

$$
H=H_{\mathrm{B}}-f_{c m n},
$$

де $H_{\text {в }}$ - висота у вільному стані зовнішньої та внутрішньої пружини, $H_{\mathrm{B}}=0,249 \mathrm{м} ; f_{c m n}-$ статичний прогин пружини.

Статичний прогин внутрішньої та зовнішньої пружини визначимо за формулами:

$$
\begin{gathered}
f_{\text {стивн }}=\frac{P_{c m}}{C_{6 н}} . \\
f_{\text {стизн }}=\frac{P_{c m}}{C_{3 н}} . \\
f_{\text {стивн }}=\frac{6,7}{148,13}=0,0452 \mathrm{M} . \\
f_{\text {стизи }}=\frac{6,7}{331,63}=0,02 \mathrm{M.} .
\end{gathered}
$$




$$
\begin{gathered}
H_{6 н}=0,249-0,0452=0,2038 \mu . \\
H_{з н}=0,249-0,02=0,229 \mu .
\end{gathered}
$$

Тоді горизонтальна жорсткість внутрішньої та зовнішної пружини становитиме:

$$
\begin{gathered}
C_{2 в}=\frac{3 \cdot 2 \cdot 10^{8} \cdot 0,019^{4}}{8 \cdot 0,105 \cdot 7,6 \cdot\left[0,2038^{2} \cdot(2+0,28)+3 \cdot 0,105^{2}\right]}=95,86 \kappa \mathrm{H} / \mathrm{M}^{2} . \\
C_{2 н}=\frac{3 \cdot 2 \cdot 10^{8} \cdot 0,030^{4}}{8 \cdot 0,172 \cdot 4 \cdot\left[0,229^{2} \cdot(2+0,28)+3 \cdot 0,172^{2}\right]}=432,9 \mathrm{\kappa H} / \mathrm{M}^{2} .
\end{gathered}
$$

Сумарна горизонтальна жорсткість комплекту пружин становитиме:

$$
C_{2}=95,86+432,9=528,76 \kappa H / \mathrm{m}^{2} .
$$

Поздовжні критичні сили, що призводять до відносного перекосу вагонів і осей автозчепів у плані, визначимо за формулами (7), (8):

$$
\begin{gathered}
N_{\kappa a}=\frac{14 \cdot 528,76}{1+\frac{7,835}{1}} \cdot \frac{6,12^{2}}{7,835}=4005,38 \kappa H . \\
N_{\kappa \tilde{\sigma}}=1 \cdot 14 \cdot 528,76=7402,64 \kappa H .
\end{gathered}
$$

Коефіцієнти $\gamma$ й $\alpha$ визначимо за формулами (5), (6):

$$
\begin{gathered}
\gamma=\frac{1}{1-\frac{500}{4005,38}}=1,14 . \\
\alpha=\frac{1-\frac{500}{4005,38}}{1-\frac{500}{7402,64}}=0,938 .
\end{gathered}
$$

Проведемо перевірку виконання умови:

$$
\delta_{y}<\left[\delta_{y}\right] .
$$

Для цього спочатку визначимо горизонтальну силу, прикладену до підп'ятника першого й другого візка:

$$
H_{1}=1,14 \cdot 500 \cdot\left[\frac{0,025 \cdot 7,835}{6,12^{2}} \cdot\left(1+\frac{7,835}{1}\right)+0,938 \cdot \frac{8,835}{250}\right]=45,23 \kappa H .
$$




$$
H_{2}=1,14 \cdot 500 \cdot\left[\frac{0,025 \cdot 7,835}{6,12^{2}} \cdot\left(1+\frac{7,835}{1}\right)-0,938 \cdot \frac{8,835}{250}\right]=7,44 \kappa H .
$$

Знайдемо пружну поперечну деформацію ресорних комплектів візків при дії поперечних горизонтальних сил $H_{1,2}$ :

$$
\begin{aligned}
& \delta_{1}=\frac{45,23}{14 \cdot 528,76}=0,006 . \\
& \delta_{2}=\frac{7,44}{14 \cdot 528,76}=0,001 .
\end{aligned}
$$

Оскільки, $\left[\delta_{\mathrm{y}}\right]=0,024$, то умова виконується $(0,006<0,24,0,001<0,24)$.

$$
\begin{gathered}
k_{y c}=\frac{109,747+2 \cdot 1,14 \cdot 500 \cdot\left(\left[\frac{0,025 \cdot 7,875}{6,12^{2}} \cdot\left(1+\frac{7,875}{1}\right) \cdot 0,801+0,938 \cdot \frac{8,835}{250} \cdot 1,04\right]\right) \cdot \frac{1}{1,6}}{0,25 \cdot 109,747+2 \cdot 1,14 \cdot 500 \cdot\left(\left[\frac{0,025 \cdot 7,875}{6,12^{2}} \cdot\left(1+\frac{7,875}{1}\right)+0,938 \cdot \frac{8,835}{250}\right] \cdot\left(1-0,25 \cdot \frac{1,04}{1,6}\right)\right.} \\
\frac{-2 \cdot 132,435 \cdot \frac{0,15}{1,6} \cdot \frac{1,485}{1,6}}{\left.-0,25 \cdot 0,938 \cdot \frac{8,835}{250} \cdot \frac{1,04-0,801}{1,6}\right)-2 \cdot 132,435 \cdot \frac{0,15}{1,6} \cdot\left(1-0,25 \cdot \frac{1,485}{1,6}\right)} \cdot \frac{1,732-0,25}{1+0,25 \cdot 1,732} \\
=1,72 .
\end{gathered}
$$

Отже, умова стійкості від сходу з рейок для вагона моделі 11-286 при другому розрахунковому випадку виконується $(1,72>1,2)$.

Проте отримані значення не $\epsilon$ досить точними. Розрахунки за зазначеними нормами не дають можливості враховувати параметри рейкової колії, а саме нерівності як у вертикальній, так і в горизонтальній площині, які зустрічаються в процесі експлуатації. Також розрахунки критеріїв безпеки руху за цими нормами не дозволяють установити вплив зносу колісних пар і рейкової колії. Крім цього, перевищення допустимого значення коефіцієнта запасу стійкості колісної пари від сходу не завжди призводить до вкочування гребеня колеса на головку рейки. Це пояснюється тим, що співвідношення вертикального навантаження до горизонтальної сили може перевищити допустиме значення, а при цьому зазор між гребенем і рейкою ще не буде вичерпаний.

\section{Висновки.}

1. Для вагона моделі 11-286 було виконано перевірку умов стійкості від сходу з рейок.

2. Коефіцієнт стійкості від сходу з рейок для вагона цієї моделі за другим розрахунковим випадком склав 1,72 , що більше допустимого значення $(1,2)$.

3. Розрахунки за прийнятими нормами не дають можливості враховувати несправності рейкової колії та зноси ходових частин рухомого складу, які трапляються в експлуатації. 
4. Створення математичних моделей вагонів дозволить ураховувати основні особливості конструкції ходових частин, знос колісних пар, рейкової колії та встановлювати момент часу, коли вичерпується зазор між гребенем колеса та рейкою (виникає їх динамічна взаємодія). Також слід проаналізувати європейський досвід у визначенні критеріїв безпеки руху.

\section{АНАЛИТИЧЕСКОЕ ОПРЕДЕЛЕНИЕ КРИТЕРИЕВ БЕЗОПАСНОСТИ ДВИЖЕНИЯ НА ЖЕЛЕЗНОДОРОЖНОМ ТРАНСПОРТЕ}

\section{Батиг A. B.}

Исследование условия устойчивости подвижного состава от схода с рельсов было выполнено многими зарубежными и отечественными учеными, каждый из которых предложил свои методы и подходы кего расчету. Каждый из предложенных методов и подходов имеет свои преимущества и недостатки, которые детально проанализированы. Кроме этого, метод определения коэффициента запаса устойчивости от схода с рельсов подвижного состава приведен в принятых в настоящее время нормах по расчету и проектированию вагонов колеи 1520 мм, в европейских нормах. Однако расчеть по нормам, которье используются для железньх дорог колеи 1520 мм, не дают возможности учитывать параметры рельсовой колеи, а именно неровности как в вертикальной, так и в горизонтальной плоскостях, которые встречаются в процессе эксплуатации. Также расчеты критериев безопасности движения по этим нормам не позволяют установить влияние износа колесных пар и рельсового пути. Кроме этого, превышение допустимого значения коэффициента запаса устойчивости колесной пары от схода с рельсов подвижного состава не всегда приводит к вкатыванию гребня колеса на головку рельса. Это объясняется тем, что соотношение вертикальной нагрузки к горизонтальной силе может превысить допустимое значение, но при этом зазор между гребнем и рейкой еще не будет исчерпан. Выполнена проверка условий устойчивости от схода с рельсов подвижного состава по принятым нормами для вагона модели 11-286. Приведены основные недостатки использованного метода расчета и способы его усовершенствования. Создание математических моделей вагонов позволит учитывать основные особенности конструкиии ходовых частей, износ колесных пар, рельсового пути и устанавливать момент времени, когда исчерпывается зазор между гребнем колеса и рельсом (возникает их динамическое взаимодействие). Также следует проанализировать европейский опыт в определении критериев безопасности движения.

Ключевые слова: сход с рельсов подвижного состава, катастрофа, авария, безопасность движения, устойчивость от схода с рельсов.

\section{ANALYTICAL DETERMINATION OF CRITERIA FOR SAFETY OF MOTION AT RAILWAY TRANSPORT}

\section{Batig A. $\boldsymbol{V}$.}

The research on rolling stock stability condition for derailment was carried out by many foreign and domestic scientists, each of them proposed its own methods and approaches to its calculation. Each of proposed methods and approaches has its advantages and disadvantages that are analyzed in detail. Besides the method of determining the stability margin coefficient for derailment of rolling stock is indicated in currently accepted norms for 
calculation and design of railcars track of $1520 \mathrm{~mm}$, in European standards. However, calculations based on the norms that are used for railways track of $1520 \mathrm{~mm}$ do not give an opportunity to take into account the parameters of the rail track, namely the irregularities in both the vertical and horizontal planes that occur during operation. So, calculations of traffic safety criteria according to these standards do not allow to determine the effect of wear of wheel pairs and rail track. Moreover exceeding the permissible value of stability margin coefficient for derailment of rolling stock does not always lead to the rolling in of the wheel flange on the railhead. Because the ratio of vertical load to horizontal force can exceed the permissible value, but the gap between the wheel flange and the bar will not be exhausted. Check of stability conditions from a derailment of rolling stock on accepted by norms for model 11-286 car is executed. The basic lacks of the used method of calculation and ways of its improvement are resulted. Creation of mathematical models of railcars will allow to take into account main features of construction of running gears, wear of wheelsets, railtrack and determine the time when the gap between the wheel flange and the rail is exhausted (their dynamic interaction arises). We should also analyze the European experience in determining the criteria for traffic safety.

Keywords: derailment of rolling stock, catastrophe, crash, traffic safety, stability from derailment.

DOI: https://doi.org/10.32353/khrife.2018.51

УДК 343.148 .6

A. Я. Кузишин, науковий співробітник Львівського НДІСЕ

E-mail: kuzyshyn1993@gmail.com, A. B. Баmiz, старший науковий співробітник Львівського НДІСЕ

E-mail: batigasha1992@gmail.com

\section{ВИКОРИСТАННЯ ДОДАТКОВОГО КРИТЕРІЮ ОЦІНЮВАННЯ БЕЗПЕКИ РУХУ ВІД СХОДУ КОЛЕСА З РЕЙКИ В СУДОВІЙ ЗАЛІЗНИЧНО-ТРАНСПОРТНІЙ ЕКСПЕРТИЗІ}

Проведено дослідження додаткового критерію оиінювання безпеки руху, відповідно до якого схід колеса з рейки аналізувався за фактичним підйомом гребеня колеса на головку рейки. Зазначена особливість дозволить детальніше дослідити розвиток механізму залізнично-транспортної пригоди.

Ключові слова: взаємодія колії та рухомого складу, схід колеса з рейки, безпека руху, механізм залізнично-транспортної пригоди.

Схід 3 рейок рухомого складу залізничного транспорту - подія, що призвела до втрати взаємодії хоча б одного колеса рухомого складу залізничного транспорту з рейкою в результаті зміщення колеса від свого нормального положення щодо головки рейки ${ }^{1}$. Слід зазначити, що першочергове завдання

1 Про затвердження Інструкції з організації відбудовних робіт при ліквідації наслідків транспортних подій на залізницях України : наказ Міністерства транспорту України від 27.04.2001 № 258. URL: zakon.rada.gov.ua/go/z0422-01Ґ. 